Journal of Applied Pharmaceutical Science Vol. 6 (07), pp. 189-192, July, 2016

Available online at http://www.japsonline.com

DOI: $10.7324 / \mathrm{JAPS} .2016 .60728$

ISSN 2231-3354 (cc)) EY-NC-SA

\title{
Pharmacological Effects of Atorvastatin in Platelet Function and Plaque Rupture
}

\author{
Pushpa Natarajan ${ }^{1}$, Suresh Kanna ${ }^{2}$, Sinu Sahl ${ }^{3}$, Pooja Sathish ${ }^{3}$, Vijaya Anand ${ }^{3 *}$ \\ ${ }^{1}$ Department of Microbiology, Cauvery College for Women, Tiruchirappalli, Tamil Nadu, India. ${ }^{2}$ Department of Chemistry, Bharathiyar College of \\ Engineering and Technology, Karaikal, Puducherry, Tamil Nadu, India. ${ }^{3}$ Department of Human Genetics and Molecular Biology, Bharatiar University, \\ Coimbatore, Tamil Nadu, India.
}

\section{ARTICLE INFO}

Article history:

Received on: 12/01/2016

Revised on: 16/03/2016

Accepted on: 18/04/2016

Available online: $28 / 07 / 2016$

Key words:

Atorvastatin; Platelet

aggregation; Platelet

function; Cardiovascular

disease.

\begin{abstract}
Platelets are a prime reason for causing cardiovascular disease (CVD). After atherosclerotic plaque rupture, platelets can form pathogenic, formation of blood clot which leads to various cardiovascular events. The beneficial effect of 3-hydroxy-3-methylglutaryl coenzyme A (HMG-Co-A) reductase inhibitors reduces CVDs clinically. The objective of this review is the pharmacological benefit of atorvastatin in CVD by platelets and plaque rupture due to high levels of cholesterol.
\end{abstract}

\section{INTRODUCTION}

Cardiovascular disease (CVD) is a major health problem and the prevalence of CVD is highest in the industrial world for last few decades (Vijaya Anand et al., 2008). Platelets are specialized cells, which involved in the formation of blood clots and circulating platelet levels are related to the formation of mural thrombus at the site of plaque rupture and vascular injury (Lacoste et al., 1995; Willerson et al., 1989). Platelet aggregation and plaque rupture can be occurred due to high levels of cholesterol which results in CVD. The risk of cardiovascular events can be reduced by atorvastatin therapy through reduction of plasma total cholesterol (TC) and low-density lipoprotein (LDL) cholesterol levels (Vijaya Anand et al., 2009).

* Corresponding Author

Vijaya Anand, Department of Human Genetics and Molecular Biology, Bharatiar University, Coimbatore, Tamil Nadu, India.

Email:avamiet@yahoo.com
Hypercholesterolemia may be related an increased platelet reactivity. This may leads the rise of the cholesterol/phospholipid ratio in platelets. The other possible mechanisms which include an increase in the biosynthesis of thromboxane $A_{2}$, the density of platelet $\alpha_{2}$-adrenergic receptor, and also platelet cytosolic calcium (Hackeng et al., 1999).

Statins induced the reduction of platelet activity has been described as a positive effect exerted by statins on the thrombotic vascular events. Puccetti et al. (2002) suggest a different impact of several statins (simvastatin $20 \mathrm{mg} /$ day, atorvastatin $10 \mathrm{mg} / \mathrm{day}$, fluvastatin $40 \mathrm{mg} /$ day and pravastatin $40 \mathrm{mg} /$ day) on platelet function, which is initially related to interference with plateletassociated-LDL cholesterol rather than LDL cholesterol reduction. Simavastatin $(\mathrm{p}<0.001)$, atorvastatin $(\mathrm{p}<0.001)$, fluvastatin $(\mathrm{p}<$ $0.01)$ and pravastatin $(\mathrm{p}<0.05)$ reduce the activity of platelet. This review particularly focuses the role of atorvastatin in platelet and plaque rupture due to abnormal level excess cholesterol. 


\section{ATORVASTATIN AND PLATELETS FUNCTION}

Platelets play a vital role in the progression of CVD (Fitzgerald et al., 1986). Hypercholesterolemia is correlated with increases in platelet reactivity (Opper et al., 1995). These abnormalities are associated with increases in the cholesterol/phospholipid ratio in platelets. Additional potential mechanisms include increases in thromboxane A2 (TXA2) biosynthesis (Notarbartolo et al., 1995), platelet $\alpha^{2}$-adrenergic receptor density (Baldassarre et al., 1997) and platelet cytosolic calcium (Le Quan Sang et al., 1995). Atorvastatin had a marked reduction effect on platelet aggregation (Tekten et al., 2004). Atorvastatin therapy can improve hemorheological parameters and platelet aggregation endothelial dysfunction (Szapary et al., 2004). Combining clopidogrel with atorvastatin in the healthy individuals led to a reduction in ADP-induced platelet p-selectin exposure. Pretreatment with atorvastatin reduces platelet reactivity before administration of clopidogrel (Piorkowski et al., 2004).

Atorvastatin and aspirin therapy in the early onset of the acute event, notably reduced persistent TXA (2) and TXA (2)dependent aspirin resistance. This may be contributing to the clinical benefit of atorvastatin in patients with myocardial infarction (Santos et al., 2009). Among percutaneous coronary intervention treated patients with high on-treatment platelet reactivity during administration of both atorvastatin and clopidogrel, switching to a non-CYP3A4-metabolized statin significantly decrease platelet reactivity. This switching effect seems to be similar irrespective of the type of non-CYP3A4metabolized statin (Park et al., 2012).

Therapy with statins successfully modifies ADP-induced platelet aggregation in hyperlipidemic patients and does not affect ADP-induced platelet adhesion to fibrinogen as well as platelet aggregation induced by collagen or ristocetin (Sikora et al., 2013). Moscardo et al. (2013), reported the direct downregulation with atorvastatin and simvastatin of platelet cPLA2 activity through effects on calcium, Mitogen-activated protein kinases (MAPK) and decrease TXA2 synthesis, which induced by collagen.

Statins significantly reduce mean platelet volume (MPV) (Sivri et al., 2013). The expression of platelets CD62p and PAC-1 is increased in $\mathrm{HNC}$ (normal high-density lipoprotein cholesterol) patients. The surface expression of platelets CD62p and PAC-1 is greater among HLC (low levels of high-density lipoprotein cholesterol) patients than among control patients. After atorvastatin treatment, the expression of CD62p and PAC-1 decreased significantly. The reduction of high-density lipoprotein (HDL) cholesterol and increased platelet activation is seen in patients with high levels of LDL cholesterol (Chan et al., 2015).

High platelet reactivity during co-administration of clopidogrel and a CYP3A4-metabolized statin (i.e. atorvastatin) can be lowered (Pelliccia et al., 2014). The MPV and red cell distribution width (RDW)is associated with an increased cardiovascular risk. There is an association between MPV, RDW and lipoprotein subfractions. After 12 weeks of treatment with atorvastatin, MPV and RDW values altered in hypercholesterolemic patients, shows atorvastatin as strongest lipid-lowering effect (Kucera et al., 2015).

In patients suspected with CVD, urinary 11-dehydro (dh) thromboxane B2 (TXB2) was determined. High thrombin-induced platelet-fibrin clot strength (TIP-FCS) indicates elevated 11-dh TXB2 associated with a prothrombotic state. Atorvastatin and aspirin therapy are major treatments for coronary artery disease (CAD) (Bliden et al., 2014).Recent studies reveal that in the thrombotic process the reactive oxygen species (ROS) are implicated. Atorvastatin are associated to redox signaling interfering, inhibition of platelet formation of NADPH oxidasederived ROS, thus exhibit antiplatelet effects atorvastatins possess antithrombotic effects, and it accounts for the reduction of thrombotic-related vascular outcomes (Violi et al., 2014).

\section{ATORVASTATIN AND PLAQUE STABILITY}

Plaque rupture is a main reason of acute coronary syndrome (ACS) (Libby, 1995). The atherosclerotic lesion comprises highly thrombogenic substances in the lipid core that are separated by a fibrous cap from the bloodstream (FernandezOrtiz et al., 1994). Ulceration of the fibrous cap ultimately leads to plaque rupture and ensuing thrombosis (Fuster et al., 1990). Collagen is the major constituent of fibrous caps, since macrophages are capable of degrading the collagen-containing fibrous cap; they play a significant role in the progress and subsequent stability of atherosclerotic plaques (Shah et al., 1995).

Certainly, degradation of the plaque matrix seems to be most active in regions with rich macrophage (Fuster et al., 1995). Secretion of Matrix metallopeptidases (MMPs) by activated macrophages may weaken the fibrous cap, mostly at the "vulnerable" shoulder region where the fibrous cap joins the arterial wall (Henney et al., 1991). This weakened fibrous cap possibly leads to plaque instability, rupture and consequently thrombosis (Davies et al., 1995). Intensive statin treatment can improve plaque stability by decreasing the plaque size or by altering the physiochemical properties of the lipid core (Koh et al., 2000; Fukumoto et al., 2001).

The plaque-stabilizing properties are mediated through a combined decrease in lipids, macrophages as well as MMPs (Crisby et al., 2001). These effects of statins may reduce the occurrence of ACS by reducing the tendency for plaque to rupture and may elucidate the rapid time course of event reduction in high risk patients for recurrent coronary ischemia in the Myocardial Ischemia Reduction with Aggressive Cholesterol Lowering (MIRACL) (Schwartz et al., 2001) and the Pravastatin or Atorvastatin Evaluation and Infection trials (PROVE-IT) (Cannon et al., 2004).

The benefits of early statin treatment to stabilize culprit lesions in ACS will directed to an increase in the proportion of coronary patients who will receive this favorable therapy (Waters et al., 2001). Shimojima et al. (2012) results confirmed that plaque composition and volume might be changed within 3 weeks following intensive lipid lowering therapy. This may explain acute effects of statins in the treatment of ACS. 
Cyclooxygenase (COX)-2 expressions is increased in inflammation and angiogenesis and also in atherosclerotic plaques, where it co-localizes with MMPs involved in weakening of the fibrous cap. The regulation of COX-2 and MMP-9 expression advocates the involvement of a Rho-dependent pathway. In the human vascular endothelium, simvastatin and atorvastatin reduce COX-2 and MMP-9 expression and activity. Through this mechanism, statins concern an anti-angiogenic effect may possibly contribute to the cholesterol-lowering-unrelated protective efficiency of statins against plaque inflammatory angiogenesis as well as rupture (Massaro et al., 2010).

In the treatment of hyperlipidemia, the statins have certain advantageous effects which include plaque stability, enhanced endothelial function, decreased oxidative stress and inflammation, to the further side of their lipid-lowering effect in plasma. The impact of atorvastatin has been evaluated on the structural/mechanical properties of erythrocyte and the lipid peroxidation in dyslipidemics. The atorvastatin treatment reduces the lipid peroxidation in plasma and erythrocytes and enhances plasma total antioxidant capacity (Uydu et al., 2012).

These observations confirmed the lipid lowering action atorvastatin may contribute to plaque stability by decreasing the size of the plaque or by altering the lipid core physiochemical properties. This plaque-stabilizing properties of atorvastatin may be mediated by the reduction of lipids. These effects of atorvastatin may reduce the incidence of ACS and an intensive lipid lowering therapy provides greater protection against major cardiovascular events a (Cannon et al., 2004).

\section{CONCLUSION}

In general, the cholesterol reduction by atorvastatin is the predominant therapeutic result underlying their beneficial effects in CVD. The effects result from the combine action on lipid lowering with positive effects on the clinical condition to normal in both plaque stabilization and platelet aggregation. This provides the important information on how to maximize the pleiotropic benefits of atorvastatin in the patients at the risk for CVD.

\section{REFERENCES}

Baldassarre D, Mores N, Colli S, Pazzucconi F, Sirtori CR, Tremoli E. Platelet alpha 2-adrenergic receptors in hypercholesterolemia: relationship between binding studies and epinephrineinduced platelet aggregation. Clin. Pharmacol. Ther. 1997;61:684-91.

Bliden KP, Singla A, Gesheff MG, Toth PP, Tabrizchi A, Ens G, Guyer K, Singh M, Franzese CJ, Stapleton D, Tantry US, Gurbel PA. Statin therapy and thromboxane generation in patients with coronary artery disease treated with high-dose aspirin. Thromb Haemost. 2014; 112(2):323-31.

Cannon CP, Braunwald E, McCabe CH. Pravastatin or atorvastatin evaluation and infection therapy-thrombolysis in myocardial infarction 22 investigators. Intensive versus moderate lipid lowering with statins after acute coronary syndromes. N Engl J Med. 2004; 350: 1495504.

Chan LW, Luo XP, Ni HC, Shi HM, Liu L, Wen ZC, Gu XY, Qiao J, Li J. High levels of LDL-C combined with low levels of HDL-C further increase platelet activation in hypercholesterolemic patients. Braz $\mathrm{J}$ Med Biol Res. 2015;48(2):167-73.
Crisby M, Nordin-Fredriksson G, Shah PK, Yano J, Zhu J, Nilsson J. Pravastatin treatment increases collagen content and decreases lipid content, inflammation, metalloproteinases, and cell death in human carotid plaques: implications for plaque stabilization. Circulation. 2001; 103:926-33.

Davies MJ.Acute coronary thrombosis-the role of plaque disruption and its initiation and prevention. Eur. Heart J. 1995;16:3-7.

Fernandez-Ortiz A, Badimon JJ, Falk E, Fuster V, Meyer B, Mailhac A, Weng D, Shah PK, Badimon L. Characterization of the relative thrombogenicity of atherosclerotic plaque components: implications for consequences of plaque rupture. J. Am. Coll. Cardiol. 1994; 23:1562-69.

Fitzgerald DJ, Roy L, Catella F, FitzGerald GA. Platelet activation in unstable coronary disease. New Engl. J. Med. 1986; 315:98389.

Fukumoto Y, Libby P, Rabkin E, Hill CC, Enomoto M, Hirouchi Y, Shiomi M, Aikawa M. Statins alter smooth muscle cell accumulation and collagen content in established atheroma ofwatanabe heritable hyperlipidemic rabbits. Circulation.2001;103:993-99.

Fuster V, Stein B, Ambrose JA, Badimon L, Badimon JJ, Chesebro JH. Atherosclerotic plaque rupture and thrombosis. Evolving concepts.Circulation. 1990;82:III47-59.

Fuster V. Elucidation of the role of plaque instability and rupture in acute coronary events. Am. J. Cardiol. 1995;76:24C-33C.

Hackeng CM, Huigsloot M, Pladet MW, Nieuwenhuis HK, van Rijn HJM, Akkerman JWN. Low-density lipoprotein enhances platelet secretion via integrin-alphaIIbbeta3-mediated signaling. Arterioscler Thromb Vasc Biol. 1999; 19:239-47.

Henney AM, Wakeley PR, Davies MJ, Foster K, Hembry R, Murphy G, Humphries S. Localization of stromelysin gene expression in atherosclerotic plaques by in situ hybridization. Proc. Natl. Acad. Sci.USA. 1991;88:8154-58.

Koh KK. Effects of statins on vascular wall:vasomotor function, inflammation, and plaque stability. Cardiovasc. Res. 2000;47:648-57.

Kucera M, Balaz D, Kruzliak P, Ciccocioppo R, Oravec S, Rodrigo L, Zulli A, Hirnerova E, Sabaka P, Komornikova A, Sabo J, Slezak P, Gaspar L. The effects of atorvastatin treatment on the mean platelet volume and red cell distribution width in patients with dyslipoproteinemia and comparison with plasma atherogenicity indicatorsA pilot study. ClinBiochem.2015;48(9):557-61.

Lacoste L, Lam JY, Hung J, Letchacovski G, Solymoss CB, Waters D. Hyperlipidemia and coronary disease. Correction of the increased thrombogenic potential with cholesterol reduction. Circulation. 1995; 92:3172-77.

Le Quan Sang KH, Levenson J, Megnien JL, Simon A, Devynck M. Platelet cytosolic $\mathrm{Ca}^{2+}$ and membrane dynamics in patients with primary hypercholesterolemia. Effects of pravastatin. Arterioscler. Thromb. Vasc. Biol. 1995;15:759-64.

Libby P. Molecular bases of the acute coronary syndromes. Circulation. 1995;91:2844-50.

Massaro M, Zampolli A, Scoditti E, Carluccio MA, Storelli C, Distante A,De Caterina R. Statins inhibit cyclooxygenase-2 and matrix metalloproteinase-9 in human endothelial cells:anti-angiogenic actions possibly contributing to plaquestability. CardiovascRes. 2010; 86(2): 31120.

Moscardo A, Vallés J, Latorre A, Madrid I,Santos MT. Reduction of platelet cytosolic phospholipase A2 activity by atorvastatin and simvastatin:biochemical regulatory mechanisms. Thromb Res.2013;131(4):e154-9.

Notarbartolo A, Davì G, Averna M, Barbagallo CM, Ganci A, Giammarresi C, La Placa FP, Patrono C. Inhibition of thromboxane biosynthesis and platelet function by simvastatin in type IIa hypercholesterolemia. Arterioscler.Thromb.Vasc. Biol. 1995;15:247-51.

Opper C, Clement C, Schwarz H, Krappe J, Steinmetz A, Schneider J,Wesemann W. Increased number of high sensitive platelets in hypercholesterolemia, cardiovascular diseases, and after incubation with cholesterol.Atherosclerosis.1995;113:211-17.

Park Y, Jeong YH, Tantry US, Ahn JH, Kwon TJ, Park JR, Hwang SJ, Gho EH, Bliden KP, Kwak CH, Hwang JY, Kim S, Gurbel PA. 
Accelerated platelet inhibition by switching from atorvastatin to a nonCYP3A4-metabolized statin in patients with high platelet reactivity (ACCEL-STATIN) study.EurHeart J. 2012;33(17):2151-62.

Pelliccia F, Rosano G, Marazzi G, Vitale C, Spoletini I, Franzoni F, Speziale G, Polacco M, Greco C, Gaudio C. Pharmacodynamic effects of atorvastatin versus rosuvastatin in coronary artery disease patients with normal platelet reactivity while on dual antiplatelet therapy--the PEARL randomized cross-over study. Eur J Pharmacol.2014;725:18-22.

Piorkowski M, Weikert U, Schwimmbeck PL, Martus P, Schultheiss HP, Rauch U.ADP induced platelet degranulation in healthy individuals is reduced by clopidogrel after pretreatment with atorvastatin. ThrombHaemost.2004;92(3):614-20.

Puccetti L, Pasqui AL, Pastorelli M, Bova G, Cercignani M, Palazzuoli A, Angori P, Auteri A, Bruni F. Time-dependent effect of statins on platelet function in hypercholesterolaemia. Eur J Clin Invest. 2002;32(12):901-8.

Santos MT, Fuset MP, Ruano M, Moscardo A,Valles J. Effect of atorvastatin on platelet thromboxane A (2) synthesis in aspirin-treated patients with acute myocardial infarction. Am J Cardiol. 2009;104(12):1618-23.

Schwartz GG, Olsson AG, Ezekowitz MD, Ganz P, Oliver MF, Waters D, Zeiher A, Chaitman BR, Leslie S, Stern T. for the Myocardial Ischemia Reduction with Aggressive Cholesterol Lowering (MIRACL) Study Investigators.Effects of atorvastatin on early recurrent ischemic events in acute coronary syndromes. The MIRACL study:a randomized controlled trial. JAMA.2001;285:1711-1718.

Shah PK, Falk E, Badimon JJ, Fernandez-Ortiz A, Mailhac A, Villareal-Levy G, Fallon JT, Regnstrom J,Fuster V. Human monocytederived macrophages induce collagen breakdown in fibrous caps of atherosclerotic plaques. Potential role of matrix-degrading metalloproteinases and implications for plaque rupture.Circulation. 1995; 92:1565-69.

Shimojima M, Kawashiri MA, Nitta Y, Yoshida T, Katsuda S, Kaku B, Taguchi T, Hasegawa A, Konno T, Hayashi K, Yamagishi M. Rapid changes in plaque composition and morphology after intensive lipid lowering therapy:study with serial coronary CT angiography. Am J CardiovascDis.2012;2(2):84-8

Sikora J, Kostka B, Marczyk I, Krajewska U, Chałubiński M, Broncel M. Effect of statins on platelet function in patients with hyperlipidemia. Arch Med Sci.2013;9(4):622-8.
Sivri N, Tekin G, Yalta K, Aksoy Y, Senen K, Yetkin E Statins decrease mean platelet volume irrespective of cholesterol lowering effect. Kardiol Pol.2013;71(10):1042-7.

Szapary L, Horvath B, Marton Z, Alexy T, Kesmarky G, Habon T, Szots M, Koltai K, Juricskay I, Czopf J,Toth K.Short-term effect of low-dose atorvastatin on haemorrheological parameters, platelet aggregation and endothelial function in patients with cerebrovascular disease and hyperlipidaemia. CNS Drugs.2004;18(3):165-72.

Tekten T, Ceyhan C, Ercan E, Onbasili AO,Turkoglu C. The effect of atorvastatin on plateletfunction in patients with CHD. Acta Cardiol.2004;59(3):311-5.

Uydu HA, Yıldırmış S, Orem C, Calapoglu M, Alver A, Kural B, Orem A.The effects of atorvastatin therapy on rheological characteristics of erythrocyte membrane, serum lipid profile and oxidative status in patients with dyslipidemia. 2012;245(11):697-705.

VijayaAnand A, Chenniappan M , Kalavathy S, Uma K , Saravanan MP, Sampath Kumar P. Redeeming Measures of Atorvastatin in the Risk Factors of Cardiovascular Diseases. International Journal of Pharmacology. 2008;4(4): 305-309.

VijayaAnand A, Chandrasekharan M, Kalavathy S, Uma K, Saravanan M.P, Mohamed SaleemGani A, Vijaya Kumar K, Senthil R, Sampath Kumar P.The influencing aspects of atorvastatin on C-reactive protein and Lipid profile in patients with stroke. International Journal of Biological Chemistry. 2009;3(1):30-34.

Violi F, Carnevale R, Pastori D, Pignatelli P.Antioxidant and antiplatelet effects of atorvastatin by Nox 2 inhibition. Trends Cardiovasc Med. 2014;24(4):142-8.

Waters DD.Early pharmacologic intervention and plaque stability in acute coronary syndromes. Am J Cardiol.2001;88(8A):30K$36 \mathrm{~K}$.

Willerson JT, Golino P, Eidt J, Campbell WB, Buja, LM. Specific platelet mediators and unstable coronary artery lesions. Experimental evidence and potential clinical implications. Circulation. 1989; 80:198-205.

\section{How to cite this article:}

Natarajan P, Kanna S, Sahl S, Sathish P, Anand V. Pharmacological Effects of Atorvastatin In Platelet Function and Plaque Rupture. J App Pharm Sci, 2016; 6 (07): 189-192. 